\title{
Spontaneous Bleed in a Patient With Thrombocytopenia Due to Multi-System Langerhan's Histiocytosis
}

\author{
Jossef Amirian ${ }^{\mathrm{a}, \mathrm{b}}$, Huy Hoang ${ }^{\mathrm{a}}$, Sumathi Kemisetti ${ }^{\mathrm{a}}$
}

\begin{abstract}
Langerhan's cell histiocytosis ( $\mathrm{LCH})$ is an uncommon disorder that can vary in presentation, ranging from single-system to multi-system organ involvement. Herein is a case of multi-system LCH in a 50 -year-old female found to have splenomegaly and severe thrombocytopenia, which resulted in a spontaneous bleed. This rare case highlights the possible occurrences which can occur with such a condition and more importantly focuses on the proper management and treatment modalities which should be available in such conditions.
\end{abstract}

Keywords: Thrombocytopenia; Langerhan's cell histiocytosis; Hematology

\section{Introduction}

Langerhan's cell histiocytosis ( $\mathrm{LCH})$ is a rare disorder that is characterized by the proliferation and infiltration of dendritic cells which are similar in morphology to Langerhan's cells of the skin and mucosa [1]. It is a disease that is most often characterized by osteolytic bone lesions but it can also vary in presentation, ranging from single-system involvement to multi-system organ involvement [2]. We report a rare case of multi-system LCH in a 50-year-old female causing splenomegaly and severe thrombocytopenia, leading to a spontaneous bleed.

\section{Case Report}

A 50-year-old Caucasian woman presented to the ED with a dif-

Manuscript accepted for publication June 30, 2015

aDepartment of Medicine, Hofstra North Shore Long Island Jewish School of Medicine, North Shore University Hospital, 300 Community Drive, Manhasset, NY 11030, USA

${ }^{b}$ Corresponding Author: Jossef Amirian, Department of Medicine, Hofstra North Shore Long Island Jewish School of Medicine, North Shore University Hospital, 300 Community Drive, Manhasset, NY 11030, USA.

Email: jossefamirian@gmail.com

doi: http://dx.doi.org/10.14740/jmc2182w fuse rash over her lower extremities, chest, and back after being seen by her hematologist. Her medical history was significant for LCH with multiple complications, including primary sclerosing cholangitis, cirrhosis, secondary hypothyroidism and diabetes insipidus caused by LCH infiltration of the gallbladder and pituitary gland. She had undergone chemotherapy with 6-mercaptopurine and then with cladribine with her most recent cycle 2 years prior. She denied any symptoms such as epistaxis, hemoptysis, hematemesis, hematuria, hematochezia, or melena.

On examination, there were diffuse, non-blanchable petechiae over her lower extremities, back and chest. Examination of the abdomen revealed splenomegaly. Labs showed pancytopenia with a platelet count of 1 . In July of 2012, her platelet count was 67. Ultrasound of the abdomen revealed a spleen $19 \mathrm{~cm}$ in length. She was given $3 \mathrm{U}$ of platelets; however, her platelet count remained at 1 . She was then given filgrastim and romiplostim in an attempt to stimulate bone marrow production of leukocytes and platelets. Her leukocyte count responded; however, her platelet count remained at 1 . A bone marrow biopsy was done which showed atypical lymphoreticular aggregates consistent with $\mathrm{LCH}$, but with a normal number of megakaryocytes with normal morphology.

Her thrombocytopenia and lack of response to platelet transfusions was attributed to platelet sequestration in the spleen. Surgical oncology was consulted and they recommended laproscopic splenectomy. Because of her high MELD score and high risk of mortality (greater than 30\% 90-day postoperative mortality), gastroenterology was consulted for clearance and an MRCP was done which showed no portal vein thrombus or hematoma. The patient was then scheduled for laproscopic splenectomy.

However the day before surgery, she began to have spontaneous bleeding. She developed both hematochezia and hematuria. On physical exam, she was pale and diaphoretic and her hemoglobin dropped from 7.5 to 6.5. She was given PRBCs. Surgical oncology was called for urgent, open splenectomy. Open splenectomy was successful and she immediately began to respond to platelet transfusions. At first her platelets were 213 , but normalized to a baseline of $30-80$. She was given platelets as needed when her platelets would drop below 20 . The patient was started on high dose steroids and given romiplostim and her platelet count stabilized at 30 - 40 without the need for platelet transfusions. She was then discharged with a slow, tapering dose of steroids. 


\section{Discussion}

This is a rare presentation of severe thrombocytopenia and spontaneous bleed in a patient with multi-system LCH. LCH is a rare disorder characterized by dysplasia and infiltration of immune cells similar in phenotype and morphology to the Langerhan's cells of the mucosa and skin single-system involvement is the most common manifestation; however, multisystem involvement does occur and usually signifies a poor prognosis and high mortality [3, 4]. LCH most commonly affects bone, skin and the lymphatic system. It can also infiltrate into the CNS, lung, liver and spleen. Infiltration into bone marrow, spleen and liver usually denote a worse prognosis. The etiology is unclear and there is continuing research to differentiate whether LCH is a malignant or reactive process [5-7]. Diagnosis is made with a biopsy of bone or skin lesions showing characteristic histiocytes with staining positive for CDla and CD207.

Treatment depends on whether there is single-system or multi-system organ involvement and whether at risk organs (bone marrow, liver, or spleen) are involved. Treatment varies widely based on the organs involved, but usually involves treatment with prednisone, vinblastine, etoposide, 6-mercaptopurine or a combination of the above. Patients with singlesystem disease have high rates of spontaneous remissions and good outcomes. Even patients with multi-system disease, but no "at risk" organ involvement generally respond well to treatment. Patients with multi-system disease that respond poorly to initial chemotherapy and those with "at risk" organ involvement generally have very poor outcomes [8-12]. Because of the rarity of the disease and its varied presentation few randomized trials have been done to study optimal treatment regimens. For this case, a search of the literature does not show optimal treatment in LCH patients with multi-system disease and splenomegaly. Further research is needed; however, this case may highlight the need for prophylactic splenectomy in LCH patients with multi-system disease with splenic involvement to prevent the serious complication of severe thrombocytopenia due to splenic sequestration.

\section{Disclosures}

All the above authors have no disclosures and no conflicts of interest.

\section{References}

1. Jaffe R. The diagnostic histopathology of Langerhans cell histiocytosis. In: Histiocytic Disorders of Children and Adults. Basic Science, Clinical Features, and Therapy, Weitzman S, Egeler RM (Eds), Cambridge University Press, Cambridge 2005. p.14.

2. Malpas JS, Norton AJ. Langerhans cell histiocytosis in the adult. Med Pediatr Oncol. 1996;27(6):540-546.

3. Grois N, Potschger U, Prosch H, Minkov M, Arico M, Braier J, Henter JI, et al. Risk factors for diabetes insipidus in langerhans cell histiocytosis. Pediatr Blood Cancer. 2006;46(2):228-233.

4. Braier JL, Rosso D, Latella A, Chantada G, Ozuna B, Ripoli M, Scopinaro M. Importance of multi-lineage hematologic involvement and hypoalbuminemia at diagnosis in patients with "risk-organ" multi-system Langerhans cell histiocytosis. J Pediatr Hematol Oncol. 2010;32(4):e122-125.

5. Nicholson HS, Egeler RM, Nesbit ME. The epidemiology of Langerhans cell histiocytosis. Hematol Oncol Clin North Am. 1998;12(2):379-384.

6. McClain K, Jin H, Gresik V, Favara B. Langerhans cell histiocytosis: lack of a viral etiology. Am J Hematol. 1994;47(1):16-20.

7. Willman CL, Busque L, Griffith BB, Favara BE, McClain KL, Duncan MH, Gilliland DG. Langerhans'-cell histiocytosis (histiocytosis X)--a clonal proliferative disease. $\mathrm{N}$ Engl J Med. 1994;331(3):154-160.

8. Abla O, Egeler RM, Weitzman S. Langerhans cell histiocytosis: Current concepts and treatments. Cancer Treat Rev. 2010;36(4):354-359.

9. Minkov M. Multisystem Langerhans cell histiocytosis in children: current treatment and future directions. Paediatr Drugs. 2011;13(2):75-86.

10. Gadner H, Grois N, Arico M, Broadbent V, Ceci A, Jakobson A, Komp D, et al. A randomized trial of treatment for multisystem Langerhans' cell histiocytosis. J Pediatr. 2001;138(5):728-734.

11. Gadner H, Grois N, Potschger U, Minkov M, Arico M, Braier J, Broadbent V, et al. Improved outcome in multisystem Langerhans cell histiocytosis is associated with therapy intensification. Blood. 2008;111(5):2556-2562.

12. Gadner H, Heitger A, Grois N, Gatterer-Menz I, Ladisch S. Treatment strategy for disseminated Langerhans cell histiocytosis. DAL HX-83 Study Group. Med Pediatr Oncol. 1994;23(2):72-80. 